\title{
Patient Journey in Atopic Dermatitis: The Real-World Scenario
}

\author{
Jose Manuel Carrascosa - Pablo de la Cueva · Raul de Lucas · \\ Eduardo Fonseca · Ana Martín · Asunción Vicente · Maria Pilar Fortes • \\ Susana Gómez · Francisco José Rebollo (iD
}

Received: July 12, 2021 / Accepted: August 11, 2021 / Published online: August 23, 2021

(C) The Author(s) 2021

\begin{abstract}
Introduction: The diagnosis and management of atopic dermatitis (AD) is extensively addressed in detailed clinical guidelines. However, the high heterogeneity regarding presentation and progression and the increasingly broad therapeutic landscape suggest a complex real-world
\end{abstract}

Supplementary Information The online version contains supplementary material available at https:// doi.org/10.1007/s13555-021-00592-y.

J. M. Carrascosa

Hospital Universitario Germans Trias i Pujol,

Badalona, Spain

P. de la Cueva

Hospital Universitario Infanta Leonor, Madrid, Spain

R. de Lucas

Hospital La Paz, Madrid, Spain

E. Fonseca

Complejo Hospitalario Universitario de La Coruña, La Coruña, Spain

A. Martín

Hospital Universitari Son Espases, Palma de

Mallorca, Spain

A. Vicente

Hospital Sant Joan de Déu, Barcelona, Spain

M. P. Fortes · S. Gómez · F. J. Rebollo ( $₫)$

Pfizer SLU, Avenida Europa 20B, Parque Empresarial

La Moraleja, 28108 Madrid, Spain

e-mail: francisco.rebollo@pfizer.com scenario, leading to multiple trajectories of $\mathrm{AD}$ patients.

Methods: Using a Delphi methodology for assessing the degree of consensus, we explored the views of a panel of dermatologists regarding the patients' trajectory through the diagnosis (block 1), treatment (block 2), and long-term management (block 3) of AD. Based on a systematic search of the literature, a scientific committee prepared a questionnaire of relevant items that were rated on a 10-point scale (from "totally agree" to "totally disagree") by a panel of dermatologists attending patients with AD in the hospital setting. Consensus was established based on predefined rules.

Results: The final questionnaire included 58 items and was answered by 17 dermatologists. Overall, consensus was reached on 22 items (37.9\%), each of which was a consensus for agreement. The consensus rates in blocks 1,2 , and 3 were $22.7 \%, 19.0 \%$, and $86 \%$, respectively.

Conclusions: Our analysis revealed a remarkable lack of consensus on various aspects of the routine diagnosis and treatment of $\mathrm{AD}$. These findings suggest the presence of unmet needs or limited implementation of guidelines for the management of $\mathrm{AD}$ and encourage further research to explore the causes of this low consensus on the management of $\mathrm{AD}$ in the realworld setting. 
Keywords: Atopic dermatitis; Diagnosis; Real world; Consensus

\section{Key Summary Points}

Why carry out this study?

Atopic dermatitis (AD) is a complex disease with a heterogeneous presentation and trajectory and a broad therapeutic repertoire.

Owing to this heterogeneous scenario, it is unclear whether dermatologists who manage $\mathrm{AD}$ patients in the real-world setting share a consistent view of the patients' journey through AD.

Using a Delphi methodology, we investigated the perception of a group of dermatologists regarding the patients' trajectory through the diagnosis, treatment, and long-term management of $\mathrm{AD}$.

\section{What was learned from the study?}

There is low consensus among dermatologists regarding essential aspects of the diagnosis, assessment, and treatment of $\mathrm{AD}$.

Our findings encourage further research to explore the extent of these inconsistencies and identify gaps in management guidance.

\section{INTRODUCTION}

Atopic dermatitis (AD) is a complex disease associated with multiple predisposing factors and a heterogeneous presentation regarding age, clinical features, and intensity of signs and symptoms [1]. AD is most frequently diagnosed in childhood; however, up to $25 \%$ of adults with $\mathrm{AD}$ report an adult onset, with differences between the early- and late-onset phenotypes [2]. Heterogeneity also exists regarding the sequence in which signs and symptoms progress through other allergic comorbidities-referred to as the "atopic march." In most cases, cutaneous manifestations precede the onset of allergic rhinitis and asthma [3, 4]. Nevertheless, allergic respiratory diseases may appear concomitantly with $\mathrm{AD}$ or even before it $[5,6]$.

This heterogeneity in the clinical presentation of $\mathrm{AD}$ broadens the repertoire of healthcare professionals aside from dermatologists (e.g., pediatricians, pneumologists, and general practitioners) who may interact with $\mathrm{AD}$ patients at the time of presentation and diagnosis. The resulting differences in care pathways may strongly influence disease trajectories [4]. In some cases, a misdiagnosis by nonspecialized professionals and/or inadequate treatment at an early stage may compromise the patient's management [7]. Likewise, heterogeneous presentations and trajectories of patients with $\mathrm{AD}$ require the therapeutic approach to be tailored to each patient profile. Dermatologists have access to exhaustive management guidelines that support therapeutic decisions in this regard [8-12]. However, missing topics and discrepancies between guidelines have been identified, underlining the limited consensus on specific aspects of disease management [13].

Regardless of these divergences, it is generally accepted that many patients achieve adequate disease control with nonpharmaceutical treatments and educational interventions $[8,12,14]$. Additionally, it may occasionally be necessary to complement maintenance therapy with treatment for acute flares and-in the most severe cases-systemic treatment. In the past few years, the development of new drugs for pharmaceutical treatment (including topical phosphodiesterase 4 inhibitors [15] and biological systemic treatments $[14,16])$ has broadened the therapeutic repertoire for $\mathrm{AD}$. The increasing trend to use therapeutic tools may continue with the emergence of systemic drugs targeting alternative steps in the atopic signaling pathway, such as Janus kinase inhibitors $[17,18]$. This growing therapeutic landscape provides dermatologists with multiple options but can also make it more challenging to select the best treatment for each patient profile, reinforcing the need for more guidance. 
Owing to the heterogeneous presentation and trajectory of $\mathrm{AD}$ patients and the complexity of the current therapeutic landscape, it is unclear whether dermatologists who manage $\mathrm{AD}$ patients in the real-world setting share a consistent view of the patients' journey through AD. In this study, we investigated the perceptions of a group of dermatologists regarding the patients' trajectory through diagnosis, treatment, and long-term management of AD.

\section{METHODS}

We used a Delphi consensus methodology to describe the trajectory of patients with $\mathrm{AD}$ through routine care in our area. Figure 1 shows an overview of the approach to defining the patient journey. The Delphi questionnaire, developed in a focus group meeting based on a state-of-the-art internal report, was structured into three blocks covering relevant stages of the trajectory of $\mathrm{AD}$ : (1) from symptom onset to diagnosis, (2) treatment, and (3) maintenance therapy and acute treatment of flares throughout long-term management. The state-of-the-art report on $\mathrm{AD}$ was prepared utilizing a set of key references (e.g., management guidelines and general reviews) along with review articles found in a systematic search of the literature published in the last five years. For this search, we combined the term "atopic dermatitis" or "atopic eczema" with the following terms associated with each of the stages covered: "sign," "symptom," "onset," "risk factors," "diagnosis," "concomitant disease," "comorbidity," "trigger event," "severity scale," "topical therapy," "nonpharmacologic," "systemic therapy," "agents" ("anti-inflammatory," "phototherapy," "phosphodiesterase," "biological"), "clearance," "efficacy scales," "maintenance therapy," "longterm care," "complementary therapies," "relapse," "flare," "adherence," "follow-up," avoidance," "adjuvant." Searches were performed using the Ovid engine in the Medline and Embase databases and were restricted to relevant peer-reviewed articles published between 2014 and 2020 in English with the full text available. A total of 246 articles met the selection criteria; of those, 80 provided relevant insights regarding any of the three blocks and were therefore selected for the state-of-the-art report. The scientific committee (i.e., all of the listed authors of this manuscript) discussed the report in a focus group meeting and proposed a list of items for the Delphi questionnaire.

The Delphi questionnaire (which is shown in its entirety in the Supplementary Information) was uploaded to an online platform and sent to a panel of dermatologists recruited by the scientific committee members from various healthcare centers in different provinces in Spain. Based on previous suggestions and the lack of substantial differences in accuracy
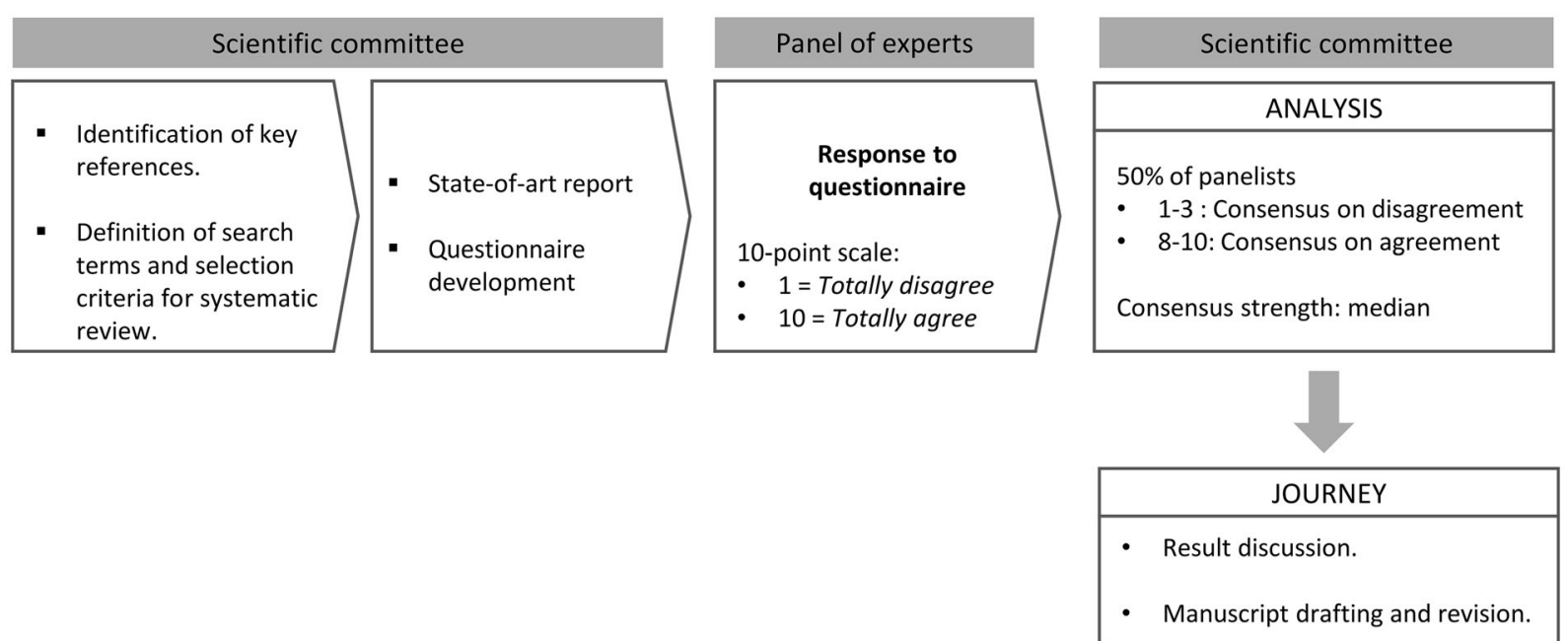

Fig. 1 Scheme of the approach used to describe the patient's journey in atopic dermatitis 
Table 1 Items in the 58-item questionnaire for which a consensus was reached

Strength of consensus (median

score; 1-10 scale)

First block: patient presentation and diagnosis

Patient journey

4 The dermatologist is the professional who usually makes the differential diagnosis of moderate-to-severe forms of $\mathrm{AD}$

5 In addition to the dermatologist, the following specialists should typically be involved in the management of patients with mild AD: pediatricians, allergists, general practitioner

Assessment of risk factors

[No items reached consensus]

Diagnosis criteria and severity rating scales

15 For the diagnosis of AD, the specialist's opinion prevails over other criteria, such as rating indexes and scales

20 Measures that assess the patient's quality of life should be added to adopt a comprehensive approach to the management of patients with $\mathrm{AD}$

21 Mobile phone apps featuring disease severity scales are useful in usual clinical practice

Second block: therapeutic approaches to the management of $\mathrm{AD}$

Emollient recommendation

23 In routine clinical practice, patients with atopic dermatitis are usually prescribed a specific emollient

Hygienic measures

24 In terms of bathing practices as nonpharmacological measures for the treatment of atopic dermatitis, a daily frequency is recommended

Educational actions

26 At the office visit, patient involvement in the treatment of atopic dermatitis is usually sought to ensure good therapeutic results

27 Educational measures are usually implemented in clinical practice to achieve greater patient involvement in the treatment of $\mathrm{AD}$ and the prevention of flares

Scope of nonpharmacological treatment

30 Adjuvant nonpharmacological treatment is essential to achieve good therapeutic results, even with the new generation of drugs used for $\mathrm{AD}$

31 In mild-moderate forms of atopic dermatitis, or between flares, nonpharmacological measures are typically proactively supplemented with preventive pharmacological treatments 
Table 1 continued

Strength of consensus (median score; 1-10 scale)

Topical treatment

32 Lesion location is more relevant than age of the patient for determining the 8 potency of a topical corticosteroid

34 Corticosteroid wet wrap therapy is a common strategy in the management of moderate-severe AD in children

35 Topical calcineurin inhibitors are used as second-line therapy after corticosteroids for the topical treatment of $\mathrm{AD}$

Phototherapy

[No items reached consensus]

Systemic therapy

44 Antihistamines are commonly prescribed in patients with moderate-severe AD

46 Based on the data available at the moment, systemic therapy with Janus kinase (JAK) inhibitors could potentially have a relevant role in the systemic treatment of patients with moderate-severe atopic dermatitis

Assessment of effectiveness

[No items reached consensus]

Third block: long-term management and flare treatment

Proactive (maintenance treatment)

52 The intermittent use of topical corticoids as maintenance therapy is common in clinical practice

53 The use of calcineurin inhibitors as maintenance therapy is common in clinical practice

Pharmacological approach to the treatment of flares

54 Stress is frequently a triggering factor in an $\mathrm{AD}$ flare

55 In the dermatological visit during a flare, factors such as a lack of treatment compliance, infection, or contact dermatitis are assessed before intensifying treatment

Patient commitment

57 "Steroid phobia" (the rejection of corticosteroids due to safety concerns) often compromises patient compliance with treatment involving these drugs

58 Low treatment compliance is a common obstacle in the long-term management of $\mathrm{AD}$ 


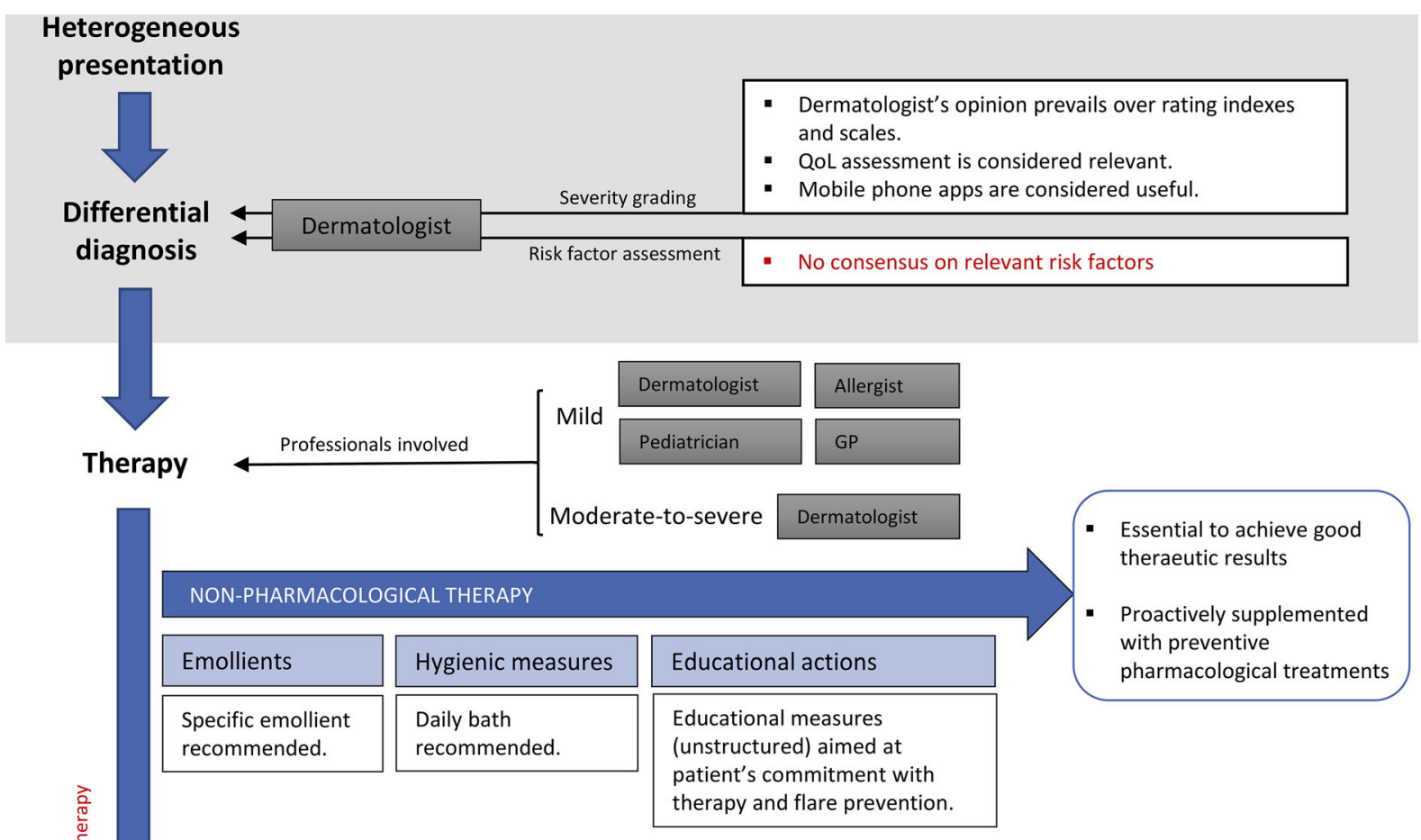

TOPICAL THERAPY

Corticosteroids

- Location is more relevant than age for chosing potency.

- Wret wrap therapy is common in moderate-to-severe $A D$ in children.

\section{PHOTOTHERAPY}

No consensus regarding its use for treating moderate-to-severe AD before starting systemic therapy

\section{SYSTEMIC THERAPY}

Classical systemic immunomodulators

Heterogeneous choice after cyclosporine and before dupilumab.

\section{Calcineurin inhibitors}

Second-line Essential to achieve good roactively supplemented with preventive pharmacological treatments patient's commitment with
therapy and flare prevention. 
4Fig. 2 Summary of the patients' journey through diagnosis, treatment, and long-term management of atopic dermatitis (AD) according to the consensus resulting from the 58-item questionnaire. Text in red highlights the lack of consensus in sections with no items for which consensus was reached (consensus corresponded to at least $60 \%$ of the panel members scoring for either agreement or disagreement)

among small Delphi groups, we sought a panel of dermatologists ranging from 5 to 20 members [19]. Delphi items were rated on a 10-point scale where 1 meant "totally disagree" and 10 "totally agree." The consensus threshold was established based on the Delphi survey technique guidelines from Hasson et al., which recommend that a level of consensus ranging from 51 to $80 \%$ (depending on the aim of the research and resources available, among other factors) should be defined [20]. Considering that our study aimed to describe the real-world scenario of $\mathrm{AD}$ management rather than to issue expert recommendations, and aligning with the consensus threshold used in a previous Delphi process focusing on atopic dermatitis [21], we defined consensus as more than $60 \%$ of participants scoring at the extreme areas of the scale: either 1-3 (consensus for disagreement) or 8-10 (consensus for agreement). The strength of consensus among the items for which a consensus was reached was measured using the median score. Items with more than $50 \%$ of experts scoring 4-7 were considered to be lacking in consensus.

In Spain, Delphi studies are not required to be reviewed by a research ethics committee as they are not considered to be biomedical research because they do not involve human subjects, samples from them, or human data.

\section{RESULTS}

The Delphi questionnaire included 58 items grouped into the three pre-established blocks $(22,27$, and 7 items for blocks 1, 2, and 3, respectively), and was answered by 17 dermatologists, all of whom attended patients with atopic dermatitis in the hospital setting. Among those dermatologists, $12(71 \%)$ treated pediatric patients frequently, 4 (23\%) did so occasionally, and $1(6 \%)$ never treated pediatric patients.

Overall, consensus was reached on 22 items (37.9\%), with a consensus for agreement reached in all cases (Table 1). Of the 22 items in the first block regarding patient presentation and diagnosis, consensus was achieved for 5 $(22.7 \%)$ items (Supplementary Fig. S1). The most substantial consensus (a median score of 10) was obtained for item 4 , which identified the dermatologist as the healthcare professional who performs the diagnosis of moderate-tosevere atopic dermatitis in routine practice, and item 20, regarding the need to perform an assessment of the quality of life in the comprehensive management of patients with atopic dermatitis. Other items with a consensus had a median score of 8 .

Panelists reached a consensus for 11 (19.0\%) of the 27 items in the second block regarding therapeutic approaches to the management of AD (Supplementary Fig. S2). The median score ranges for items with a consensus for agreement ranged from 7 to 9 .

Of the seven items in the third block regarding long-term management and flare treatment, consensus (all for agreement) was reached for six (86\%); see Supplementary Fig. S3. The item regarding AD patients having a good level of knowledge about their condition and treatment did not reach consensus, with $77 \%$ of the participants rating in the undetermined region of the scale.

Figure 2 summarizes the patients' journey through diagnosis, treatment, and long-term management of $\mathrm{AD}$, according to the consensus items obtained from the questionnaire.

\section{DISCUSSION}

\section{From Symptoms to Diagnosis}

In line with previous reviews reporting on the heterogeneity of clinical presentation at the time of $\mathrm{AD}$ diagnosis [1], $77 \%$ of the panelists scored in the undetermined range when asked about the presence of other atopic comorbidities at diagnosis. Likewise, the presence of AD during childhood in newly diagnosed adults did 
not reach consensus, with only $47 \%$ of the panelists scoring for agreement. The heterogeneous presentation of $\mathrm{AD}$ at diagnosis also applied to risk factors; a lack of consensus regarding the presence of nonatopic comorbidities has been identified elsewhere $[5,22]$. Such comorbities include psychological disorders and lifestyle behaviors associated with high cardiovascular risk.

Regarding the type of care, there was consensus on the fact that different professionals (e.g., GPs and pediatricians, if applicable) should be involved in the management of patients with mild $\mathrm{AD}$; on the other hand, all panelists agreed on the central role of dermatologists in the diagnosis of moderate-to-severe $\mathrm{AD}$. However, this finding must be placed in the context of all the panelists being dermatologists, meaning that they are more likely to highlight the importance of the dermatologist in the journey of atopic dermatitis patients. Regardless of the potential bias of this view, the importance of the dermatologist in the differential diagnosis of $\mathrm{AD}$ has been identified, as they are crucial to preventing the misdiagnosis of patients presenting with signs and symptoms of $\mathrm{AD}$ that may be compatible with other skin disorders such as inflammatory, infectious, malignant, or congenital diseases [7].

In addition to the heterogeneous presentation of $\mathrm{AD}$, various authors have suggested that there is a lack of standardized diagnostic criteria of AD, particularly for adults [4]. Furthermore, some guidelines acknowledge the limitations of the Hanifin and Rajka criteria (currently the gold standard for $\mathrm{AD}$ diagnosis) in a real-life setting [9]. Dermatologists in our panel did not reach a consensus for agreement or disagreement regarding the lack of consolidated criteria for $\mathrm{AD}$ diagnosis. The same trend was observed for the definition of flares, with $53 \%$ of the panelists (i.e., 7\% below the consensus threshold) agreeing on the lack of a standard definition of flares. Regardless of opinions about the consistency of clinical definitions of $\mathrm{AD}$ and flares across guidelines, there was strong consensus (76\% scored for agreement) on the superiority of the opinion of the dermatologist over assessment scales when diagnosing AD. Participants also reached consensus regarding the usefulness of apps for rating severity (65\% agreement) and the need to assess quality of life to establish a comprehensive management plan for $\mathrm{AD}$ in routine practice ( $88 \%$ agreement).

\section{Treatment}

Most guidelines agree that skin hygiene and hydration are the building blocks of initial AD treatment $[8,11,14]$. Consistent with this recommendation, the panel of experts reached consensus on the relevance of adjuvant nonpharmacological therapy for achieving good therapeutic results. Of note, there was also consensus (65\% agreement) on proactively supplementing nonpharmacological measures with pharmacological treatments for preventing flares in mild-to-moderate AD. Nonpharmacological therapies are unevenly addressed in current guidelines, and inconsistencies exist regarding specific recommendations on the halting of moisturizer components and the use of bath additives [13]. Most members of the panel recommended a specific emollient (65\% agreement) and a daily bath (71\% agreement), but there was no consensus on recommending bath additives such as sodium hypochlorite (12\% agreement, 53\% undetermined).

Irrespective of specific recommendations regarding nonpharmacological therapy, various authors have highlighted the need to promote the involvement of patients in their treatment [23-25]. We found a strong consensus on the need for patients to be committed to their therapy ( $82 \%$ agreement), and the need to provide patients with educational measures to achieve patient commitment (65\% agreement). However, no consensus was reached regarding the utilization of an $\mathrm{AD}$ school or educational measures to improve specific outcomes such as sleep quality or itching management. The relevance of these educational measures is increasingly being acknowledged, particularly in childhood, where nocturnal itching - and the subsequent sleep disturbance-may affect cognitive development [22].

Topical corticosteroids (TCS) are the building blocks of topical therapy for AD $[8,11]$. Panel members reached a consensus (71\% agreement) 
that they considered lesion location to be a more relevant factor than age when deciding upon the appropriate potency of TCS. A consensus was also reached regarding the frequent use of wet wrap therapy in children (65\% agreement). This approach has raised controversy, with some authors warning about a lack of evidence regarding its efficacy compared with the direct application of TCS [26] and uneven support for it in therapeutic guidelines [13]. It is worth mentioning that the concept of wet wrap therapy is not homogeneous and may encompass various modalities with different levels of evidence.

Other topical agents such as topical calcineurin inhibitors (TCI) and-more recentlythe phosphodiesterase- 4 inhibitor crisaborole may contribute to topical therapy [14]. Although comparative analyses of the efficacies and safety of TCS and TCI remain an unmet need [27], a consensus statement from the European Academy of Dermatology and Venereology explicitly recommends TCS as firstline therapy [28]. Accordingly, experts have shown a broad consensus regarding the use of TCI as second-line therapy (82\% agreement). However, there are divergences regarding the ability of current topical agents to control pruritus and the value of new therapeutic approaches-such as phosphodiesterase-4 inhibitorsin topical therapy for AD.

Phototherapy and systemic therapy (with cyclosporine as first-line treatment) are recommended for patients for whom topical treatment does not achieve adequate symptom control $[8,11]$. In our work, the percentage of panel members who agreed that phototherapy should commonly be used in moderate-to-severe cases of $\mathrm{AD}$ before starting systemic therapy was below the consensus threshold (59\% agreement). Likewise, no consensus was reached on the preferred immunomodulatory agent (i.e., methotrexate, azathioprine, or mycophenolate, asked sequentially on the same page of the questionnaire) to prescribe before biological agents in cases of treatment failure with cyclosporine: $59 \%$ of panel members disagreed with choosing mycophenolate, and there was no consensus for either agreement or disagreement with a preference for methotrexate and azathioprine. This finding may be explained by the complexity of case-mix recommendations for these systemic agents $[29,30]$, but also by the increasing adoption of biologic therapies as part of regular systemic therapy for moderate-to-severe AD [31].

Biologic systemic therapies for moderate-tosevere AD are currently limited to dupilumab, which blocks the intercellular signaling of interleukin-4 (IL-4) and interleukin-13 (IL-13). However, other new therapies in the late-phase of drug development, such as the Janus kinase inhibitors (JAKi) abrocitinib, baricitinib, and upadacitinib, are broadening the systemic therapy repertoire $[15,18]$. The panel of experts showed a strong consensus ( $82 \%$ agreement) on the significant potential of JAKi for the treatment of moderate-to-severe $\mathrm{AD}$ in the near future.

\section{Maintenance Therapy and Acute Treatment of Flares Throughout Long- Term Management}

For most patients with mild disease, nonpharmacological interventions provide adequate maintenance therapy [14]. Still, subclinical inflammation may persist even after lesions disappear [32], thus requiring topical treatments in susceptible areas. This therapy is mostly based on TCS, although TCI and emerging drugs such as crisaborole may be combined or alternated with TCS [15, 27]. Experts in our panel reached a strong consensus on the frequent administration of intermittent TCS (71\% agreement) and TCI (88\% agreement) for maintenance therapy.

The treatment of periodic flares presents a challenge in the long-term management of AD. Guidance in this regard is often hampered by the lack of a standardized definition of a flare (which is also missing in the research setting) [33]. The strong consensus (77\% agreement) that stress is a triggering factor for flares indicates that dermatologists are aware of the need for a comprehensive approach to flare prevention. Management of flares should also take factors such as low adherence, infection, or contact dermatitis into account before scaling 
up pharmacological therapy (77\% agreement). This approach is supported by evidence that flares without remission after seven days of TCS therapy are often associated with adherence issues or other clinical conditions such as Staphylococcus aureus infection or contact dermatitis [14].

Regardless of hygiene and pharmacological interventions for managing $\mathrm{AD}$ in the long term, successful therapy has increasingly been associated with adequate patient knowledge of the disease and self-care [34]. Patient education should not be limited to transferring information at the time of diagnosis or prescribing new treatments; instead, it has been proposed that it should be an evolving process in which the patient acquires knowledge and abilities associated with disease management [24]. The question regarding the level of knowledge of patients about $\mathrm{AD}$ and its management did not yield a consensus, with $77 \%$ of participants scoring in the undetermined range. Conversely, a strong consensus was observed regarding adherence as an important barrier to the longterm success of $\mathrm{AD}$ therapy ( $88 \%$ agreement), and corticophobia - a relatively extended phenomenon [35, 36] —as an important contributor to low adherence (82\% agreement).

Measurements of treatment effectiveness and disease progression provide the basis for stepping up AD treatment [14]. This assessment should be performed using specific scales for AD and should rule out the presence of comorbidities that may manifest through similar symptoms. However, various authors have noted that scales typically used in the research setting are not suitable for measuring disease severity and progression in routine practice [37]. Furthermore, although some scales (e.g., the EASI or the SCORAD) are considered adequate for measuring disease progression and severity, the type of information each scale provides is unclear [38]. Overall, our panelists showed a low level of consensus regarding the frequency of use of specific scales. A high percentage of the panelists (53\%) agreed with the frequent use of the Investigator Global Assessment (IGA) to make decisions about treatment scale-up, although this percentage was below the consensus threshold. To complement the general assessment of $\mathrm{AD}$ severity, it has been suggested that quality of life or symptoms with a high impact on the patients' life, such as pruritus, should be explicitly assessed [22, 39]. Panel members did not reach a consensus on the need for a systematic assessment of pruritus (53\% agreement) or quality of life when deciding whether to scale up treatment $(59 \%$ disagreed with the frequent use of quality of life measurements such as the Infants' Dermatitis Quality of Life Index, proposed due to its use in routine practice) $[40,41]$.

\section{CONCLUSIONS}

Dermatologists have access to broad-in-scope and detailed guidelines for the diagnosis and management of patients with AD. Nevertheless, the plethora of disease onsets, presentation characteristics, and trajectories of $\mathrm{AD}$ patients lead to a heterogeneous day-to-day practice scenario. Our description of the trajectories of $\mathrm{AD}$ patients receiving routine care based on the Delphi methodology suggests a low consensus level among a group of dermatologists regarding essential aspects of the diagnosis, assessment, and treatment of AD. Our findings, obtained from a group of dermatologists, encourage further research to explore the extent of these inconsistencies across the territory and the reasons for limited consensus on the management of $\mathrm{AD}$ in the real-world setting.

\section{ACKNOWLEDGEMENTS}

The authors would like to thank all dermatologists who contributed to the study by kindly answering the questionnaire: Jose Manuel Azaña, Antoni Azón, Ana Batalla, Iván Cervigón, Laia Cutro, Marta Feito, Ángeles Florez, Ángela Hernández, Francisco Javier Ortiz, Sara Palencia, Marta Pascual, Rubén del Río, Ester Roe, Julia Sánchez, Esther Serra, Juan Francisco Silvestre, Jesús Torcedor. 
Funding. Pfizer SLU (Madrid, Spain) provided funding for the study and the Journal's Rapid Service fees.

Editorial Assistance. Editorial and analytical assistance in the preparation of this article were provided by Dr. Gerard Carot-Sans and Enrique Galindo on behalf of Bio-Press. Support for this assistance was funded by Pfizer SLU (Madrid, Spain).

Authorship. All named authors meet the International Committee of Medical Journal Editors (ICMJE) criteria for authorship for this article, take responsibility for the integrity of the work as a whole, and have given their approval for this version to be published.

Author Contributions. JMC, PdlC, RdL, EF, AM, AV, MPF, SG, and FJR made substantial contributions in study design. JMC, RdL, EF, $\mathrm{AM}, \mathrm{AV}, \mathrm{MPF}$, and FJR contributed in data collection. JMC, PdlC, AV, MPF, SG, and FJR contributed to data analysis. Results were interpreted by JMC, PdlC, RdL, EF, AM, AV, MPF, SG, and FJR. The manuscript was drafted by JMC and FJR and critically revised by JMC, PdlC, RdL, EF, AM, AV, MPF, SG, and FJR, who approved the final version of the manuscript.

Disclosures. JMC has received honoraria or fees as investigator, speaker, and/or advisor from Pfizer, Sanofi, Lilly, Abbvie, Leo-Pharma, and UCB. PdlC has received honoraria or fees as consultant, advisory board member, investigator and/or speaker from Abbvie, Almirall, Astellas, Biogen, Boehringer, Celgene, Janssen, LEO Pharma, Lilly, MSD, Novartis, Pfizer, Roche, Sanofi, and UCB. RdL has received honoraria as principal investigator from Abbvie and Lilly. EF has received honoraria or fees as consultant or advisory board member from Pfizer, and grants for attending conferences from Sanofi. AM has received honoraria or fees as consultant from Pfizer, Leo, Sanofi, Abbvie, and Lilly. AV has received honoraria as principal investigator from Abbvie, Amryt, Boehringer, Celgene, Lilly, Galderma, Novartis, Pfizer, and Sanofi. MPF, SG, and FJR are emploees of Pfizer SLU.
Compliance with Ethics Guidelines. In Spain, Delphi studies are not required to be reviewed by a research ethics committee as they are not considered as biomedical research because they do not involve human subjects, their samples or their data.

Data Availability. The datasets generated during and/or analyzed during the current study are available from the corresponding author on reasonable request.

Open Access. This article is licensed under a Creative Commons Attribution-NonCommercial 4.0 International License, which permits any non-commercial use, sharing, adaptation, distribution and reproduction in any medium or format, as long as you give appropriate credit to the original author(s) and the source, provide a link to the Creative Commons licence, and indicate if changes were made. The images or other third party material in this article are included in the article's Creative Commons licence, unless indicated otherwise in a credit line to the material. If material is not included in the article's Creative Commons licence and your intended use is not permitted by statutory regulation or exceeds the permitted use, you will need to obtain permission directly from the copyright holder. To view a copy of this licence, visit http://creativecommons.org/licenses/by$\mathrm{nc} / 4.0 /$.

\section{REFERENCES}

1. Amat F, Soria A, Tallon P, Bourgoin-Heck M, Lambert $\mathrm{N}$, Deschildre A, et al. New insights into the phenotypes of atopic dermatitis linked with allergies and asthma in children: an overview. Clin Exp Allergy. 2018;48(8):919-34.

2. Lee HH, Patel KR, Singam V, Rastogi S, Silverberg JI. A systematic review and meta-analysis of the prevalence and phenotype of adult-onset atopic dermatitis. J Am Acad Dermatol. 2019;80(6):15261532.e7.

3. Spergel JM, Paller AS. Atopic dermatitis and the atopic march. J Allergy Clin Immunol. 2003;112(6): S118-27. 
4. Lebwohl MG, Del Rosso JQ, Abramovits W, Berman B, Cohen DE, Guttman-Yassky E, et al. Pathways to managing atopic dermatitis: consensus from the experts. J Clin Aesthet Dermatol. 2013;6(7 Suppl): S2.

5. Gilles S, Akdis C, Lauener R, Schmid-Grendelmeier $P$, Bieber T, Schäppi $G$, et al. The role of environmental factors in allergy: a critical reappraisal. Exp Dermatol. 2018;27(11):1193-200.

6. Paller AS, Spergel JM, Mina-Osorio P, Irvine AD. The atopic march and atopic multimorbidity: many trajectories, many pathways. J Allergy Clin Immunol. 2019;143(1):46-55.

7. Deleuran M, Vestergaard C. Clinical heterogeneity and differential diagnosis of atopic dermatitis. Br J Dermatol. 2014;170(Suppl. 1):2-6.

8. Eichenfield LF, Ahluwalia J, Waldman A, Borok J, Udkoff J, Boguniewicz M. Current guidelines for the evaluation and management of atopic dermatitis: a comparison of the Joint Task Force Practice Parameter and American Academy of Dermatology guidelines. J Allergy Clin Immunol. 2017;139(4): S49-57.

9. Eichenfield LF, Tom WL, Chamlin SL, Feldman SR, Hanifin JM, Simpson EL, et al. Guidelines of care for the management of atopic dermatitis: Section 1. Diagnosis and assessment of atopic dermatitis. J Am Acad Dermatol. 2014;70(2):338-51.

10. Sidbury R, Davis DM, Cohen DE, Cordoro KM, Berger TG, Bergman JN, et al. Guidelines of care for the management of atopic dermatitis: Section 3 . Management and treatment with phototherapy and systemic agents. J Am Acad Dermatol. 2014;71(2):327-49.

11. Wollenberg A, Barbarot S, Bieber T, Christen-Zaech S, Deleuran M, Fink-Wagner A, et al. Consensusbased European guidelines for treatment of atopic eczema (atopic dermatitis) in adults and children: part II. J Eur Acad Dermatol Venereol. 2018;32(6): 850-78.

12. Wollenberg A, Oranje A, Deleuran M, Simon D, Szalai Z, Kunz B, et al. ETFAD/EADV Eczema Task Force 2015 position paper on diagnosis and treatment of atopic dermatitis in adult and paediatric patients. J Eur Acad Dermatol Venereol. 2016;30(5): 729-47.

13. LePoidevin LM, Lee DE, Shi VY. A comparison of international management guidelines for atopic dermatitis. Pediatr Dermatol. 2019;36(1):36-65.

14. Boguniewicz M, Fonacier L, Guttman-Yassky E, Ong PY, Silverberg J, Farrar JR. Atopic dermatitis yardstick: practical recommendations for an evolving therapeutic landscape. Ann Allergy Asthma Immunol. 2018;120(1):10-22.e2.

15. Lansang P, Lam JM, Marcoux D, Prajapati VH, Spring S, Lara-Corrales I. Approach to the assessment and management of pediatric patients with atopic dermatitis: a consensus document. Section III: treatment options for pediatric atopic dermatitis. J Cutan Med Surg. 2019;23(5 suppl):19S31S.

16. Fundación de ciencias del medicamento y productos sanitarios. Informe del Grupo de trabajo en Dermatitis Atópica: del diagnóstico a la definición de de una ruta asistencial [Internet]. 2019. https:// www.fundacionfundamed.org/doc/GrupoTrabajo_ Dermatitis-Atopica.pdf. Cited 28 May 2020.

17. Gooderham MJ, Forman SB, Bissonnette R, Beebe JS, Zhang W, Banfield C, et al. Efficacy and safety of oral Janus kinase 1 inhibitor abrocitinib for patients with atopic dermatitis: a phase 2 randomized clinical trial. JAMA Dermatol. 2019;155(12):1371-9.

18. Newsom M, Bashyam AM, Balogh EA, Feldman SR, Strowd LC. New and emerging systemic treatments for atopic dermatitis. Drugs. 2020;1.

19. Rowe G, Wright G. Expert opinions in forecasting: the role of the Delphi technique. In: Principles of forecasting. Boston: Springer; 2001. p. 125-44.

20. Hasson F, Keeney S, McKenna H. Research guidelines for the Delphi survey technique. J Adv Nurs. 2000;32(4):1008-15.

21. Schmitt J, Langan S, Stamm T, Williams HC. Core outcome domains for controlled trials and clinical recordkeeping in eczema: International Multiperspective Delphi Consensus Process. J Invest Dermatol. 2011;131(3):623-30.

22. Boozalis E, Grossberg AL, Püttgen KB, Cohen BA, Kwatra SG. Itching at night: a review on reducing nocturnal pruritus in children. Pediatr Dermatol. 2018;35(5):560-5.

23. Chong JH, Koh MJA. Non-topical management of recalcitrant paediatric atopic dermatitis. Arch Dis Child. 2017;102(7):681-6.

24. Barbarot S, Stalder JF. Therapeutic patient education in atopic eczema. Br J Dermatol. 2014;170(Suppl. 1):44-8.

25. Ridd MJ, King AJL, Le Roux E, Waldecker A, Huntley AL. Systematic review of self-management interventions for people with eczema. Br J Dermatol. 2017;177(3):719-34.

26. González-López G, Ceballos-Rodríguez RM, González-López JJ, Feito Rodríguez M, Herranz-Pinto P. 
Efficacy and safety of wet wrap therapy for patients with atopic dermatitis: a systematic review and meta-analysis. Br J Dermatol. 2017;177(3):688-95.

27. Nankervis H, Thomas KS, Delamere FM, Barbarot $\mathrm{S}$, Smith S, Rogers NK, et al. What is the evidence base for atopic eczema treatments? A summary of published randomized controlled trials. Br J Dermatol. 2017;176(4):910-27.

28. Remitz A, De Pità O, Mota A, Serra-Baldrich E, Vakirlis E, Kapp A. Position statement: topical calcineurin inhibitors in atopic dermatitis. J Eur Acad Dermatol Venereol. 2018;32(12):2074-82.

29. Gooderham M, Lynde CW, Papp K, Bourcier M, Guenther L, Gulliver W, et al. Review of systemic treatment options for adult atopic dermatitis. J Cutan Med Surg. 2017;21(1):31-9.

30. Roekevisch E, Spuls PI, Kuester D, Limpens J, Schmitt J. Efficacy and safety of systemic treatments for moderate-to-severe atopic dermatitis: a systematic review. J Allergy Clin Immunol. 2014;133(2):429-38.

31. Lynde CW, Bourcier M, Gooderham M, Guenther L, Hong $\mathrm{CH}$, Papp KA, et al. A treatment algorithm for moderate to severe atopic dermatitis in adults. J Cutan Med Surg. 2018;22(1):78-83.

32. Tang TS, Bieber T, Williams HC. Are the concepts of induction of remission and treatment of subclinical inflammation in atopic dermatitis clinically useful? J Allergy Clin Immunol. 2014;133(6):1615-1625.e1.

33. Langan SM, Schmitt J, Williams HC, Smith S, Thomas KS. How are eczema "flares" defined? A systematic review and recommendation for future studies. Br J Dermatol. 2014;170(3):548-56.

34. Sokolova A, Smith SD. Factors contributing to poor treatment outcomes in childhood atopic dermatitis. Australas J Dermatol. 2015;56(4):252-7.
35. Wernham AGH, Veitch D, Grindlay DJC, Rogers NK, Harman KE. What's new in atopic eczema? An analysis of systematic reviews published in 2017. Part 1: treatment and prevention. Clin Exp Dermatol. 2019;44(8):861-7.

36. Juhász MLW, Curley RA, Rasmussen A, Malakouti M, Silverberg N, Jacob SE. Systematic review of the topical steroid addiction and topical steroid withdrawal phenomenon in children diagnosed with atopic dermatitis and treated with topical corticosteroids. J Dermatol Nurses Assoc. 2017;9(5):233-40.

37. Price A, Cohen DE. Assessment of pruritus in patients with psoriasis and atopic dermatitis: subjective and objective tools. Dermatitis. 2014;25(6): 334-44.

38. Charman C, Chambers C, Williams H. Measuring atopic dermatitis severity in randomized controlled clinical trials: what exactly are we measuring? J Invest Dermatol. 2003;120:932-41.

39. Yosipovitch G, Simpson EL, Bushmakin AG, Cappelleri JC, Luger T, Ständer S et al. Assessment of pruritus in atopic dermatitis. Itch. 2018;1.

40. Heinl D, Prinsen CAC, Sach T, Drucker AM, Ofenloch R, Flohr C, et al. Measurement properties of quality-of-life measurement instruments for infants, children and adolescents with eczema: a systematic review. Br J Dermatol. 2017;176(4): 878-89.

41. Hill MK, Kheirandish Pishkenari A, Braunberger TL, Armstrong AW, Dunnick CA. Recent trends in disease severity and quality of life instruments for patients with atopic dermatitis: a systematic review. J Am Acad Dermatol. 2016;75(5):906-17. 